\title{
The Amino Acid Sequence of Rabbit Muscle Triose Phosphate Isomerase
}

\author{
By P. H. CORRAN and S. G. WALEY \\ Sir William Dunn School of Pathology, University of Oxford, Oxford OX1 3RE, U.K.
}

(Received 24 July 1974)

\begin{abstract}
The amino acid sequence of rabbit muscle triose phosphate isomerase was deduced by characterizing peptides that overlap the tryptic peptides. Thiol groups were modified by oxidation, carboxymethylation or aminoethylation, and proteolytic digestions were carried out with chymotrypsin, pepsin or thermolysin. About 50 peptides that provided information about overlaps were isolated; the peptides were mostly characterized by their compositions and $N$-terminal residues. The peptide chains contain 248 amino acid residues, and no evidence for dissimilarity of the two subunits that comprise the native enzyme was found. The sequence of the rabbit muscle enzyme may be compared with that of the coelacanth enzyme (Kolb et al., 1974): $84 \%$ of the residues are in identical positions. Similarly, comparison of the sequence with that inferred for the chicken enzyme (Furth et al., 1974) shows that $87 \%$ of the residues are in identical positions. Limited though these comparisons are, they suggest that triose phosphate isomerase has one of the lowest rates of evolutionary change. An extended version of the present paper has been deposited as Supplementary Publication SUP 50040 (42 pages) at the British Library (Lending Division) (formerly the National Lending Library for Science and Technology), Boston Spa, Yorks. LS23 7BQ, U.K., from whom copies can be obtained on the terms given in Biochem. J. (1975) 145, 5.
\end{abstract}

Triose phosphate isomerase (EC 5.3.1.1) is the enzyme in glycolysis that is responsible for the conversion of dihydroxyacetone phosphate into D-glyceraldehyde 3-phosphate, and the structure and function of this enzyme are now being much studied. In particular, the three-dimensional structure of the enzyme from chicken muscle is being elucidated (Banner et al., 1971) and in connexion with this work the amino acid sequences of the tryptic peptides of the chicken muscle enzyme have been determined (Furth et al., 1974). The complete sequence of the coelacanth enzyme has been elucidated in an investigation notable for economy of time and material (Kolb et al., 1974). It was the rabbit muscle enzyme, however, which was first studied crystallographically (Johnson \& Waley, 1967), and so this was the protein first studied chemically (Burton \& Waley, 1968; Miller \& Waley, 1971a). The amino acid sequences of the tryptic peptides have been reported (Corran \& Waley, 1974), and compared with the results on the chicken muscle enzyme; there is such a high degree of homology that the complete sequence of the chicken muscle enzyme can be inferred with some confidence from that of the rabbit muscle enzyme. The latter is the subject of the present paper.

There are two residues of methionine in the polypeptide chain, and the three fragments obtained by cleavage with $\mathrm{CNBr}$ are readily separated; peptide 'maps' showed which tryptic peptides the fragments contained. The next step towards isolating peptides that overlapped the tryptic peptides was to use chymotryptic digests of the maleylated protein to obtain peptides containing lysine (Butler et al., 1969). Another procedure was to cleave the citraconylated protein (Dixon \& Perham, 1968) with trypsin so as to isolate large peptides obtained by cleavage at the relatively few arginine bonds. Both these procedures were attended with rather moderate success. Many of the required 'overlap peptides' (peptides overlapping two or more tryptic peptides) were in fact obtained from digestions with thermolysin, and with pepsin. Fractionation on Sephadex G-25 and G-50 columns and by electrophoresis at $\mathrm{pH} 1.8$ were often useful; the faster peptides (on electrophoresis) from a given fraction off the Sephadex column will contain basic amino acids, and the way that the mobility depends on the charge and molecular weight is known (Offord, 1966). Peptides that lack basic amino acids do not establish overlaps; only the overlap peptides are described here.

The evidence for the sequence given in Fig. 4 is described below. We believe that no other sequence is as likely on the evidence that we give, and thus the structure shown is the best working hypothesis. Fortunately, although crystallographers demand sequences, they can often check them. 
A preliminary account of this work has been given (Corran \& Waley, 1973).

\section{Materials and Methods}

Enzymes

Rabbit muscle triose phosphate isomerase was obtained from Boehringer Corp. (London) Ltd., London W.5, U.K. Trypsin (twice-crystallized, salt-free), crystalline bovine chymotrypsin, porcine pepsin and carboxypeptidase A were from Worthington Biochemical Corp., Freehold, N.J., U.S.A. Subtilisin was from Novo Terapeutisk Laboratorium, Copenhagen, Denmark. Thermolysin was from Serva, Heidelberg, Germany.

\section{Purification of peptides and sequence methods}

The procedures were as described by Corran \& Waley (1974) and Miller \& Waley (1971a); paper chromatography was carried out in solvent BAWP, butan-1-ol-acetic acid-water-pyridine (15:3:12:10, by vol.) (Waley \& Watson, 1953); electrophoretic mobility at pH6.5 was relative to aspartic acid, which was taken as -1.0 (Offord, 1966).

\section{Amino acid analysis}

Peptides were hydrolysed as described earlier (Miller \& Waley, 1971a). Duplicate samples of the two larger $\mathrm{CNBr}$ fragments were hydrolysed for 24,48 and $72 \mathrm{~h}$ at $108^{\circ} \mathrm{C}$; the values for serine and threonine were obtained by extrapolation to zero time, and the values for valine and isoleucine were obtained from the longer times. The results in Table 1 were calculated on the basis that the sum of the number of residues of aspartic acid, glycine, leucine, phenylalanine and arginine was 21 for fragment $\mathbf{M}$, and that this sum for aspartic acid, glutamic acid, glycine, alanine, leucine, phenylalanine and arginine was 87 residues for fragment $R$. The amino acid analyser was a Bio-Cal 100, equipped with a highsensitivity colorimeter, and the buffers were essentially those of Moore et al. (1958), except that the $\mathrm{pH} 3.25$ buffer was $2 \%(\mathrm{v} / \mathrm{v})$ in methanol to improve the resolution of serine and threonine. A one-column system was mostly used, at $55^{\circ} \mathrm{C}$; aminoethylcysteine and lysine were separated by eluting with the pH4.25 and pH 6.45 buffers; the column had been equilibrated with the pH 3.25 buffer.

\section{Peptide nomenclature}

The tryptic peptides (Corran \& Waley, 1974) are given the prefix $T$. The peptides obtained by the action of thermolysin, chymotrypsin and pepsin are denoted by $\mathrm{Th}, \mathrm{C}$ and $\mathrm{P}$ respectively. Peptides obtained from $\mathrm{CNBr}$ fragments $\mathrm{M}$ and $\mathrm{R}$ are so called.

\section{Modification of thiol groups}

(a) Oxidation with performic acid [ 1 vol. of $30 \%$ (w/v) $\mathrm{H}_{2} \mathrm{O}_{2}$ and $9 \mathrm{vol}$. of formic acid] was carried out on freeze-dried salt-free protein for $3.5 \mathrm{~h}$ at $4^{\circ} \mathrm{C}$; the oxidized protein was isolated by dilution with water and freeze-drying (Hirs, 1956).

(b) Alkylation with sodium iodo[ $\left[2-{ }^{14} \mathrm{C}\right]$ acetate was carried out as described by Miller \& Waley (1971a).

(c) Aminoethylation (Raftery \& Cole, 1963) was carried out as follows. After dialysis against $0.1 \%$ $\mathrm{NH}_{4} \mathrm{HCO}_{3}$ and freeze-drying, the protein $(116 \mathrm{mg})$ was dissolved in buffer made by adding $4 \mathrm{~g}$ of guanidine hydrochloride (BDH, Poole, Dorset, U.K.; purified) and $70 \mu \mathrm{l}$ of mercaptoethanol to $6 \mathrm{ml}$ of $3 \mathrm{M}$-Tris, containing $0.4 \mathrm{mg}$ of EDTA $/ \mathrm{ml}$, adjusted to pH8.6 with acetic acid. The solution was kept for $1 \mathrm{~h}$ (in a $\mathrm{N}_{2}$ atmosphere), and then treated with three portions of $0.15 \mathrm{ml}$ of ethyleneimine at intervals of $20 \mathrm{~min}$, and then kept for a further $1 \mathrm{~h}$ all under $\mathrm{N}_{2}$. Mercaptoethanol $(1 \mathrm{ml})$ was added to react with the excess of ethyleneimine, and the protein precipitated with $100 \mathrm{ml}$ of chilled ethanol. The precipitate was spun down, washed three times with $20 \mathrm{ml}$ of $95 \%(\mathrm{v} / \mathrm{v})$ ethanol, and dried $(110 \mathrm{mg})$; amino acid analysis gave 4.9 residues of aminoethylcysteine/chain (mol.wt. 26600).

\section{Cleavage with $\mathrm{CNBr}$}

The carboxymethylated protein was cleaved as described by Miller \& Waley (1971a). The aminoethylated protein was cleaved as follows. The aminoethylated protein $(110 \mathrm{mg})$ was dissolved in $2.5 \mathrm{ml}$ of formic acid, and $1.1 \mathrm{ml}$ of water was added, followed by $0.24 \mathrm{ml}$ of $10 \%(\mathrm{w} / \mathrm{v}) \mathrm{CNBr}$ in $70 \%(\mathrm{v} / \mathrm{v})$ formic acid containing $3.2 \mathrm{mg}$ of methionine $/ \mathrm{ml}$. After $20 \mathrm{~h}, \mathrm{~N}_{2}$ was bubbled through the solution, and then $12 \mathrm{ml}$ of water was added before freeze-drying. The residue in $5 \mathrm{ml}$ of water was adjusted to $\mathrm{pH} 7.2$ with $3 \% \mathrm{NH}_{3}$ solution, and the precipitate was washed twice with $3 \mathrm{ml}$ of water. The precipitate $(74 \mathrm{mg})$ is fragment $R$. The basis for the fractionation by solubility is that, when the aminoethylated protein is used, the largest $\mathrm{CNBr}$ fragment will have an isoelectric point near neutrality and the smaller fragments will be positively charged at $\mathrm{pH} 7$.

The supernatant (and washings) were fractionated on a column $(145 \mathrm{~cm}$ high $\times 2.5 \mathrm{~cm}$ diam. $)$ of Sephadex G-50, eluted with $0.5 \% \mathrm{NH}_{4} \mathrm{HCO}_{3}$ in $10 \%(\mathrm{v} / \mathrm{v})$ propan-2-ol. Fractions $(10 \mathrm{ml})$ were collected at $30 \mathrm{ml} / \mathrm{h}$; fragment $M$ emerged in fractions $39-44$, and fragment $L$ in fractions 70-76. Analyses are given in Table 1. 
Table 1. Amino acid composition of rabbit muscle triose phosphate isomerase, tryptic peptides and CNBr fragments

The values are given as residues per peptide. The values in column (1) are medians recalculated from published values (Norton et al., 1970; Krietsch et al., 1970; Miller \& Waley, 1971a) on the basis of a total of 248 residues. The values in column (2) are derived from the sum of the tryptic peptides. The values in columns (3), (5) and (7) are the medians or chosen values from analyses for the small, medium and large $\mathrm{CNBr}$ fragments respectively, and in columns (4), (6) and (8) are the values calculated from the sequence in Fig. 4.

(1)

$\begin{array}{lrr}\text { Asp } & 21 & 21 \\ \text { Thr } & 15 & 15 \\ \text { Ser } & 12 & 12 \\ \text { Glu } & 29 & 27 \\ \text { Pro } & 10 & 10 \\ \text { Gly } & 24 & 24 \\ \text { Ala } & 27 & 27 \\ \text { Val } & 24 & 25 \\ \text { Ile } & 14 & 15 \\ \text { Leu } & 15 & 15 \\ \text { Met } & 2 & 2 \\ \text { Tyr } & 4 & 4 \\ \text { Phe } & 8 & 8 \\ \text { His } & 4 & 4 \\ \text { Lys } & 21 & 21 \\ \text { Arg } & 8 & 8 \\ \text { Cys } & 5 & 5 \\ \text { Trp } & 5 & 5 \\ \text { Total } & 248 & 248\end{array}$

15

4

21

5

5
248
(3)

Fragment $\mathbf{L}$

1.0

1.2

0.7

2.0

0.9

0.9

$\begin{array}{lrl} & & 4.0 \\ 1.9 & 2 & 1.2 \\ & & 2.3 \\ 1.7 & 2 & 6.0 \\ 1.0 & 1 & 1.7 \\ 0.7 \dagger & 1 & 2.0^{*} \\ & 14 & \end{array}$

(5)

Fragment $\mathrm{M}$

8.0

5.9

1.2

5.5

5.8

4.8

9.3

5.2

3.7

2

8

* As aminoethylcysteine.

$\uparrow$ Estimated from $E_{280}$, and $\varepsilon=5.5 \mathrm{litre} \cdot \mathrm{mmol}^{-1} \cdot \mathrm{cm}^{-1}$ (Beaven \& Holiday, 1952).

(6)

8
6
1
5
5
5
10
5
4
4
1
2
2
6
2
2

68
(7)

Fragment R

12.2

9.1

9.3

21.5

4.6

16.5

17.0

19.3

10.8

11.0

2.2

4.3

3.5

13.0

5.1

2.4*

Present
(8)

12

9
10

22

4

17

16

19

11

11

2

4

4

13

5

3

4
166

\section{Enzymic digests}

The oxidized protein was digested with thermolysin, and the digest was fractionated by gel filtration on the coupled columns of Sephadex G-50 and G-25; subsequent steps in the purification of the peptides are given in Table 2 of Supplementary Publication SUP 50040. The structures of these peptides are shown in Figs. 1-3. Twelve peptides that established overlaps were obtained, and one more (Th 12) was isolated from a thermolysin digest of carboxymethylated protein.

Several chymotryptic digests were investigated, and 25 chymotryptic peptides that established overlaps were isolated (Table 3 of Supplementary Publication 50040). Oxidized protein was treated with maleic anhydride, and the maleylated protein was digested with chymotrypsin. The digest was fractionated by gel filtration and paper electrophoresis at $\mathrm{pH} 6.4$; the maleyl groups were removed in acid, and the electrophoresis was repeated. Peptides $\mathrm{C} 1-\mathrm{C} 7$ were obtained from this digest. Peptides $\mathrm{C} 14-\mathrm{C} 16$ were obtained from peptide 'maps' of fractions from gel filtration of a chymotryptic digest of oxidized protein. Peptides C8-C13 were obtained from a chymotryptic digest of aminoethylated protein; the digest was fractionated by paper electrophoresis at $\mathrm{pH} 6.5$ and $\mathrm{pH} 1.8$, and paper chromatography in solvent BAWP. Peptides containing lysine or arginine were sought by concentrating on the fractions with relatively high mobility at $\mathrm{pH} 1.8$. Further chymotryptic peptides were obtained from the $\mathrm{CNBr}$ fragments. The radioactive peptides C23 and C24 were obtained from a 'map' of a digest of the large $\mathrm{CNBr}$ fragment (fragment $\mathrm{R}$ ) derived from protein alkylated with sodium iodo$\left[2-{ }^{14} \mathrm{C}\right]$ acetate. Relatively large peptides (MC1-MC6) were obtained by limited digestion of $\mathrm{CNBr}$ fragment M with $10 \mu \mathrm{g}$ of chymotrypsin $/ \mathrm{ml}(20 \mathrm{~min}$, room temperature, in $0.25 \% \mathrm{NH}_{4} \mathrm{HCO}_{3}$ ).

Most of the peptic peptides (Figs. 2 and 3 ) described in Table 4 of Supplementary Publication SUP 50040 were obtained from digests of $\mathrm{CNBr}$ fragments from aminoethylated protein: peptides MP1 and MP3 from fragment M, and P8-P14 from fragment R. Peptide P15 is a peptide thought to contain tryptophan obtained from a digest of fragment $R$ that had been treated with $o$-nitrophenylsulphenyl chloride (Scoffone et al., 1968). o-Nitrophenylsulphenyl chloride $(2.45 \mathrm{mg})$ in acetic acid $(1 \mathrm{ml})$ was rapidly added to a stirred solution of fragment $R(17.2 \mathrm{mg})$ in $2 \mathrm{ml}$ of $50 \%(\mathrm{v} / \mathrm{v})$ acetic acid. The yellow protein was

Vol. 145 
precipitated with acetone and digested with pepsin. Peptides P1-P6 were obtained from the digest described by Miller \& Waley (1971b); thiol groups had not been modified, so the pooled peptides were oxidized with performic acid and then fractionated on Sephadex G-25 in $0.5 \%$ formic acid.

Tryptic digestion of citraconylated protein gave six peptides, E1-E6 (Figs. 2 and 3) (see Table 5 of Supplementary Publication SUP 50040); the protein had been carboxymethylated before citraconylation in guanidinium chloride. After digestion with trypsin, the citraconyl groups were removed at $\mathrm{pH} 3$ and the digest was treated with soya-bean trypsin inhibitor before fractionation by gel filtration and paper electrophoresis.

Experimental details of how these digestions were carried out are given in the text of Supplementary Publication SUP 50040. The structures of the peptides obtained were deduced from their compositions and $\mathrm{N}$-terminal residues; thus little of the overlapping was based on independent sequence analysis of the 'overlap' peptides.

\section{Results and Discussion}

\section{Tryptic peptides}

The set of peptides obtained from tryptic digests (Miller \& Waley, 1971a; Corran \& Waley, 1974) is believed to be complete, but further work was needed on two of the peptides, T2 and T5. The former (peptide 2 of Miller \& Waley, 1971a) has been digested further with subtilisin to establish the sequence in the $C$-terminal region. Subsequent partial acid hydrolysis of the main peptide containing carboxymethylcysteine gave a peptide containing only carboxymethylcysteine and lysine, and this establishes the sequence Thr-CysLys in this region of the protein (Fig. 3, residues 216-218). The tryptic peptide T5 (peptide 5 of Miller \& Waley, 1971a) has been isolated again and found to contain histidine but not lysine (in the earlier analysis histidine was mistaken for lysine); our attention was drawn to an error in the sequence of this peptide by the results obtained by J. I. Harris and his co-workers (personal communication) and referred to below. The $C$-terminal part of the peptide T5 was digested with subtilisin, and the following peptides isolated: Val-Val-Leu, Gly-His and Ser-GluArg. The sequence in this region of the protein is thus as shown in Fig. 3 (residues 91-98).

\section{Order of the fragments obtained by cleavage with $\mathrm{CNBr}$}

The polypeptide chain contains two residues of methionine, and cleavage with $\mathrm{CNBr}$ gave three fragments, called fragments $L, M$ and $R$, the last being $C$-terminal (Miller \& Waley, 1971a). Fragment M has $N$-terminal asparagine (or aspartic acid), and fragment $\mathrm{L}$ has $N$-terminal alanine. The protein has $N$-terminal alanine (Burton \& Waley, 1968), and so the order of the $\mathrm{CNBr}$ fragments is: $\mathrm{L}-\mathrm{M}-\mathrm{R}$.

\section{Amino acid sequence of the first CNBr fragment}

This, the smallest $\mathrm{CNBr}$ fragment, has 14 amino acid residues, including one residue (from the $E_{280}$ ) of tryptophan; $C$-terminal homoserine is present (Miller $\&$ Waley, 1971a). After digestion of fragment $L$ with trypsin, a basic peptide was obtained; its composition [Ser (0.9), Pro (1.3), Ala (0.9), Arg (0.8)] identifies it as peptide T17 (Corran \& Waley, 1974). Then the composition of the remainder of fragment $L$, in particular the presence of two residues of phenylalanine, is consistent with the presence of only one of the tryptophan-containing tryptic peptides, namely T22. The residue of lysine is placed from the peptides Th7 and C1 (Fig. 1, residues 1-6). The latter was obtained from the maleylated protein; the electrophoretic mobility of this peptide at pH6.5 was -0.76 before demaleylation, and +0.8 after demaleylation. This large change in mobility suggested that the charge of the maleylated peptide was -2 , and the charge of the demaleylated peptide was +2 (Butler et al., 1969). The position of elution from the Sephadex columns made it unlikely that peptide $\mathrm{C1}$ had 12 residues, and the amino acid analysis showed that peptide $\mathrm{C} 1$ was a hexapeptide containing one residue of lysine and one of arginine. These results suggested that peptide $\mathrm{C} 1$ was derived from the $N$-terminus of the peptide chain, and that the $N$ terminal alanine residue (Burton \& Waley, 1968) was maleylated. Digestion of peptide $\mathrm{Cl}$ with trypsin gave the tetrapeptide T17 and a dipeptide containing phenylalanine and lysine. These results are accommodated by the structure shown in Fig. 1.

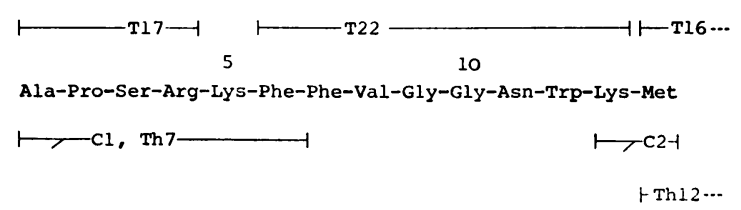

Fig. 1. Structure of smallest CNBr fragment $(L)$

The $C$-terminal residue is shown as methionine here, rather than homoserine or its lactone. The tryptic peptides are shown above the sequence; overlap peptides are shown below. C, Th, peptides obtained by digestion with chymotrypsin or thermolysin respectively. $N$-terminal amino acids are indicated thus: $\rightarrow$ 


\section{Amino acid sequence of the second $\mathrm{CNBr}$ fragment}

The amino acid composition of fragment $\mathbf{M}$ is given in Table 1; tryptophan and histidine are absent. The following tryptic peptides (Corran \& Waley, 1974) are present: T1, T3, T12, T31 and T95; all but the last were identified on peptide 'maps', and there is good agreement between the composition calculated from these peptides (and parts of T16 and T94) and that found from analysis (Table 1, columns 5 and 6).

The $N$-terminal amino acid was aspartic acid or asparagine, and a basic tryptic peptide from fragment $\mathrm{M}$, not detected in 'maps' of the whole protein, had the composition: Asp (0.8), Gly (1.1), Arg (1.1). These results, together with the sequence of the tryptic peptide T16, are accounted for by the sequence: Asn-Gly-Arg . . . as residues $15-17$ in the chain (Fig. 2). The peptides Th12, MP1 and MC1 (Fig. 2) confirm this suggestion, and provide evidence for the overlaps of peptides T16, T95 and T31.

The $C$-terminal end of peptide T31 is Ala-Ala-Lys, and this tripeptide was obtained from tryptic digests of fragment $M$. There are several reasons for thinking that the tripeptide arises because trypsin cleaves the bond between asparagine-29 and alanine-30, a type of cleavage for which there are precedents (Ambler \& Brown, 1967). One of the peptides obtained by tryptic digestion of citraconylated protein (E1, Fig. 2) apparently arises from tryptic cleavage of this bond, and indeed another peptide, E2 (Fig. 2), gave AlaAla-Lys on incubation with trypsin. The composition of fragment $M$ (Table 1) would hardly permit the presence of two more residues of alanine, i.e. 12 residues altogether; the value found from six analyses (expressed as mean \pm s.D.) was $9.18 \pm 0.45$.

There are several peptides that overlap the tryptic peptides T31 and T1 : the chymotryptic peptides MC2 and $\mathrm{MC} 3$, the thermolysin peptide Th1, and the peptic peptide MP3 (Fig. 2). Again, there are several peptides that overlap peptides T.1, T12 and T3 (Fig. 2). Peptide MC6 overlaps peptides T3 and T94, but only by one residue, and the same applies to peptides $\mathrm{C} 3$, C4 and P2; peptides C3 and C4 probably differ only in whether residue 71 is asparagine or aspartic acid, a feature also found with the tryptic peptide T94 (Corran \& Waley, 1974). The overlap of only one residue means that we have to rely on the composition of fragment $\mathbf{M}$ for confirmation that none of the tryptic peptides from this fragment have been missed. The sequence . . . Tyr-Lys-Val . . offers cleavage points for chymotrypsin, trypsin and thermolysin, and so presents difficulties. Fortunately, though, peptide T94 must be placed at the $C$-terminal end of fragment $\mathbf{M}$, because it contains the methionine that is cleaved; the composition of fragment $M$ (Table 1) shows that it contains the first 14 residues of peptide T94 and the last three residues of the other methionine peptide $T 16$, rather than the alternative arrangement, and also the $N$-terminal amino acid of fragment $\mathrm{M}$ is aspartic acid.

These results lead to the sequence given in Fig. 2.

\section{Amino acid sequence of the third $\mathrm{CNBr}$ fragment}

We come now to the third, and largest, $\mathrm{CNBr}$ fragment, R. Here 18 tryptic products have to be ordered, 16 peptides and two free amino acids. This was the most difficult part of the work, and it is here that the conclusions are least secure. Ten different kinds of digest were required to provide a minimum set of overlap peptides. At the outset, we knew from peptide 'maps' (Miller \& Waley, 1971a) which tryptic peptides fragment $R$ contained, but we had not placed the fifth cysteine peptide T5, which does not travel well on paper. In fact, this is the first tryptic peptide and follows the larger methionine peptide T94. Three peptides provided evidence for this overlap: they are Th8, C23 and P8 (Fig. 3); the cysteine residue was present as cysteic acid, $\left[2-{ }^{14} \mathrm{C}\right]$ carboxymethylcysteine and aminoethylcysteine respectively. The tryptophan was detected in (and liberated by carboxypeptidase from) peptide P8.

Peptides Th10, P9 and C5 give the overlaps T5arginine-T10. Peptide C5 apparently arises from an unusual chymotryptic fission of an Arg-Arg bond. This part of the sequence (residues 83-122) was confirmed, and, in one position, corrected by the use of the Beckman Sequencer on fragment R (J. Bridgen, E. Kolb \& J. I. Harris, personal communication). The T10-T4 overlap is provided by peptides $\mathrm{P} 3$ and $\mathrm{C} 14$, and the T4-T9 overlap by peptide P4. The structure of peptide P4 was confirmed by cleavage with trypsin: one peptide, with $\mathrm{N}$-terminal isoleucine, had the composition glutamic acid (1.4), glycine $(0.9)$, isoleucine $(0.9)$, lysine $(0.9)$, and the other, with $\mathrm{N}$-terminal leucine, had the composition aspartic acid (1.0), glutamic acid (1.1), leucine (0.9). The T4-T9 overlap is confirmed, and the next one (T9-T8) established, by peptides Th2 and C9, and peptide P10 also overlaps peptide T9 and T8.

So far there have been several peptides to establish each overlap, but now we come to a stretch where the junctions of the tryptic peptides are only overlapped by single peptides. Peptide C9 overlaps peptides T8 and T30. To be sure, there is another overlapping peptide, P11, but this only overlaps to the extent of one (unhelpful) residue. Peptides T30 and T29 are overlapped by peptide P12; this is one of the series of peptic peptides that stretches continuously from isoleucine-127 to tryptophan-157.

The next overlap proved particularly difficult to establish. We suspected that we were seeking a tryptophan peptide, and so we used $o$-nitrophenylsulphenyl chloride (Scoffone et al., 1968) to label the tryptophan residues, before digestion with pepsin. 
P. H. CORRAN AND S. G. WALEY

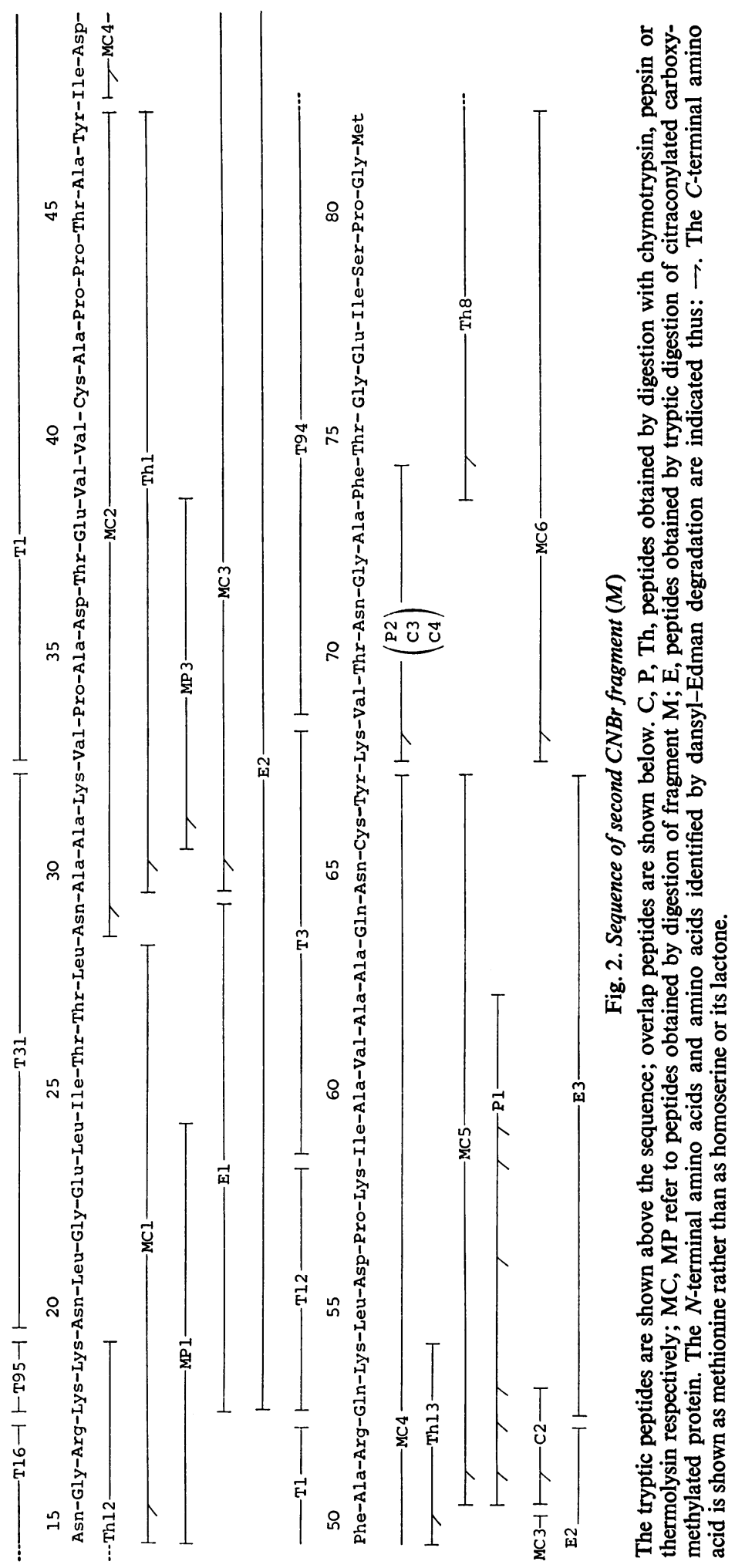




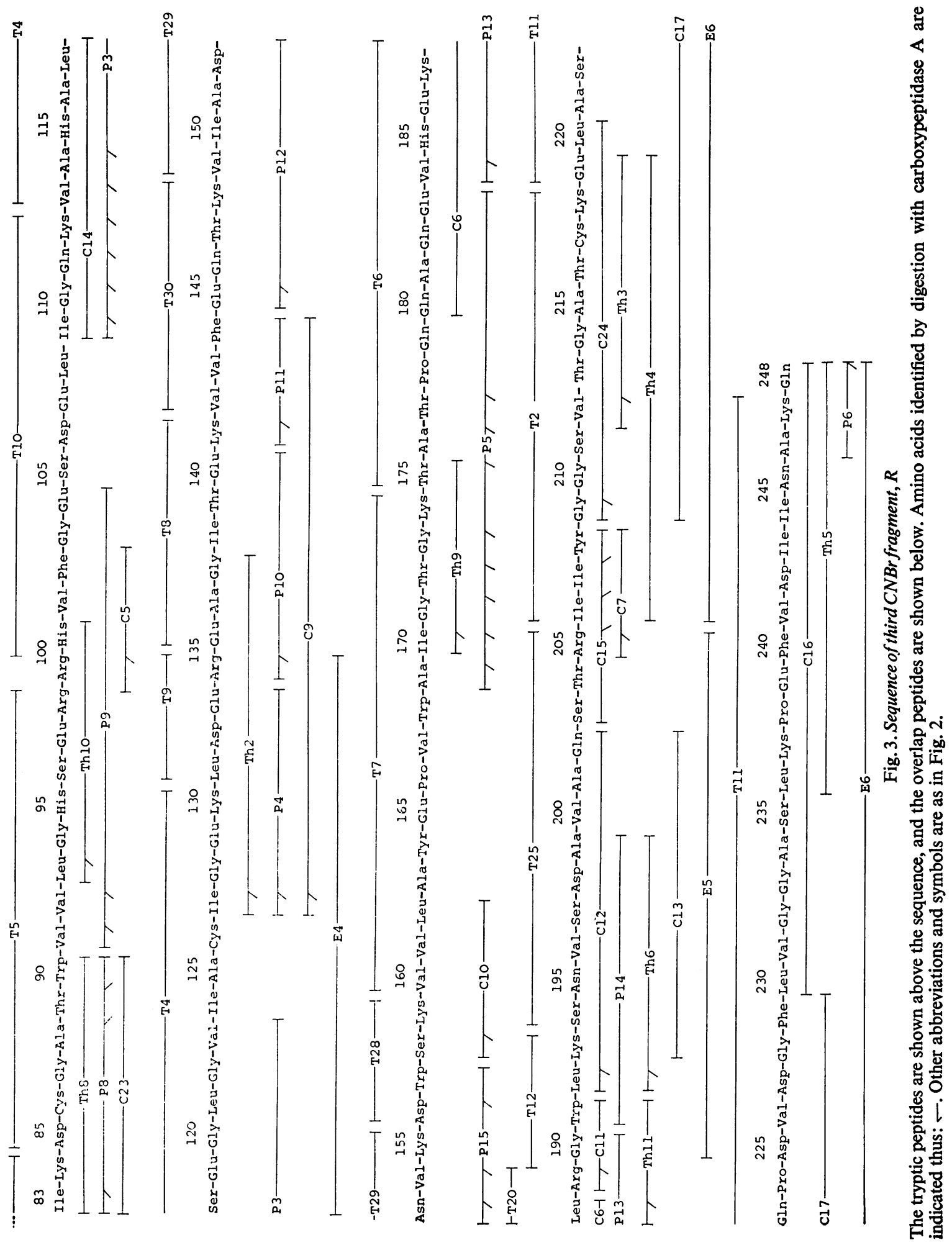

Vol. 145 


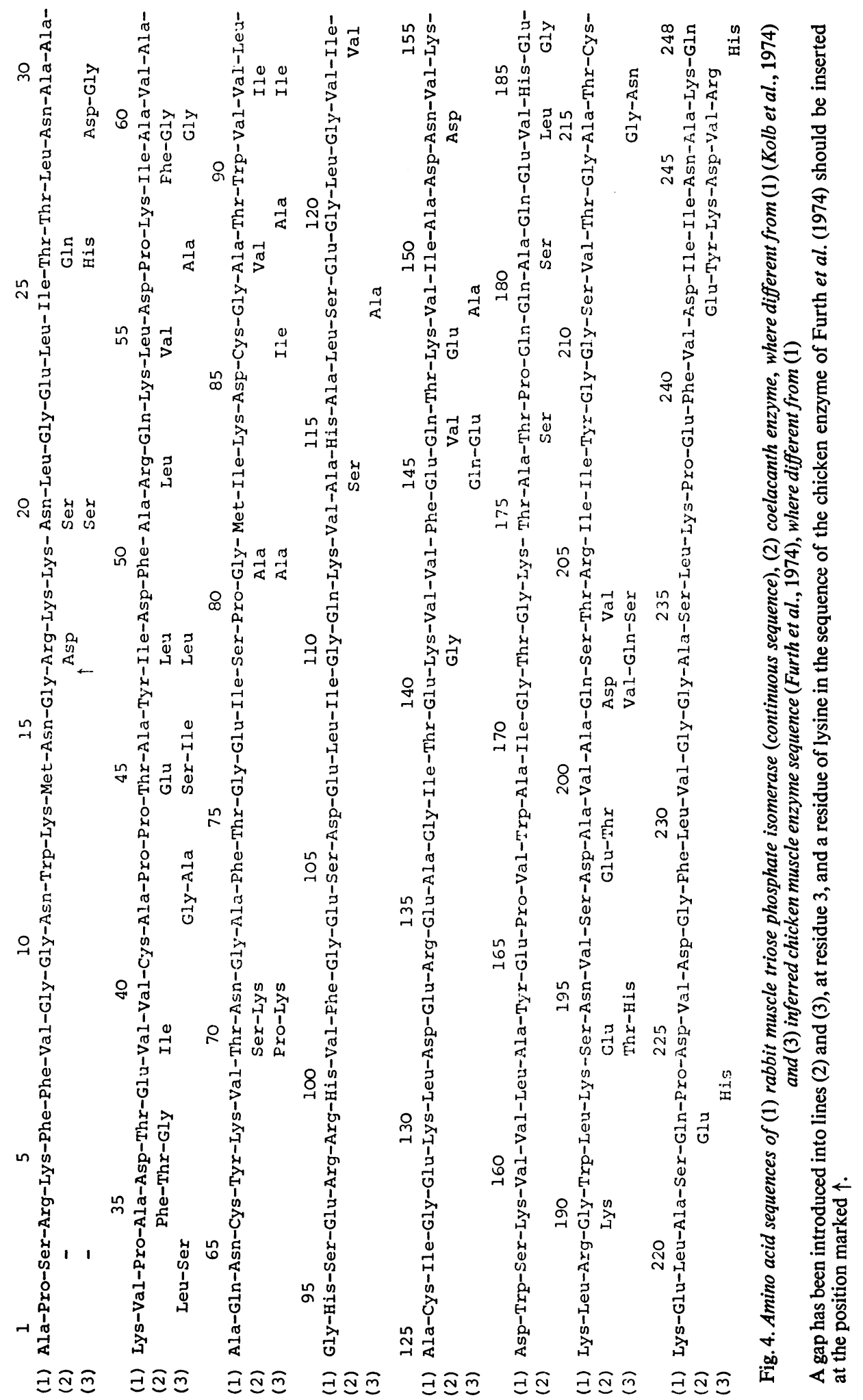


The digest was fractionated on Sephadex G-25 in $0.5 \%$ formic acid; electrophoresis at $\mathrm{pH} 6.5$ gave a yellow band adsorbed at the origin, which was then fractionated by paper chromatography in solvent BAWP. The slowest ninhydrin-positive band was peptide P15 (no other peptide was obtained from this digest), and although impure, the composition and sequence (Fig. 3) of this peptide did provide evidence for a T29-T28 junction. Peptide C10 then overlapped peptides T28 and T7. From peptide T7 onwards, there are several overlapping peptides and we are back on firm ground again. Although the region that has just been discussed is the least securely overlapped, if we assume that the three peptides T30, T29 and T28 have to be inserted in between the end of peptide $\mathrm{T} 8$ and the beginning of $\mathrm{T} 7$, then there are two independent lines of argument, one based on peptides C9 and P12 and the other based on peptides $\mathrm{C} 10$ and P15, that lead to the order T30-T29-T28 rather than any other of the six permutations.

Peptides Th9 and P5 overlap T7 and T6, and peptides $\mathrm{C} 6$ and $\mathrm{P} 13$ overlap T6 and T20; peptide $\mathrm{C} 6$ lacked an $N$-terminal amino group, and this may be ascribed to cyclization of the $N$-terminal glutamine during removal of the maleyl group from the lysine; the mobilities at $\mathrm{pH} 6.5$ were -0.5 and -0.33 before and after removal of the maleyl group. Trypsin liberated leucine from peptide C6. Peptides Th11, C11 and P13 overlap T20 and T21, whereas peptides C12, C13, P14 and Th6 overlap T21 and T25. Similarly, tryptic digestion of the citraconylated protein gave a peptide (E5) arising by cleavage at arginine-189 and arginine-205. Peptides T25 and T2 are overlapped by peptides $\mathrm{C} 15$ and $\mathrm{C7}$, and peptides $\mathrm{T} 2$ and $\mathrm{T} 11$ by several peptides, including C24, Th3 and Th4. Glutamine is the $C$-terminal residue of the whole chain (Burton \& Waley, 1968) and of this $\mathrm{CNBr}$ fragment (Miller \& Waley, 1971a) and peptide P6 confirms the $C$-terminus.

\section{Sequence homology}

The sequence deduced from the work just described is shown in Fig. 4, where it is compared with the sequence of the coelacanth enzyme (Kolb et al., 1974) and the inferred sequence of the chicken enzyme (Furth et al., 1974). There are 41 amino acid substitutions when the coelacanth enzyme is compared with the rabbit enzyme, rather more than the 32 substitutions when the comparison is with the chicken enzyme (Corran \& Waley, 1974), and there are 52 substitutions when the chicken and coelacanth enzymes are compared. Kolb et al. (1974) estimated the rate of evolution as two substitutions per 100 bonds per 100 million years, and the additional comparisons do not alter this estimate appreciably. As far as can be told from so few examples, triose

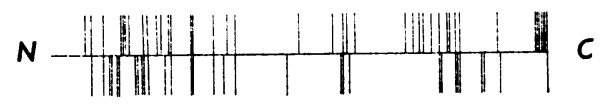

Fig. 5. Bar chart showing positions in which coelacanth (upper) and chicken (lower) muscle triose phosphate isomerase differ from rabbit muscle enzyme

The $N$-terminus is on the left. The sequences are given in Fig. 4; gaps and insertions are not represented here.

phosphate isomerase has changed at a rate comparable with that of glyceraldehyde 3-phosphate dehydrogenase and rather more slowly than cytochrome $c$ (Dayhoff, 1972).

Comparison of the sequences of the isomerases (Fig. 4) shows that there are few interchanges in the region between residues 90 and 180 , and indeed there appear to be two 'conserved' stretches centred around residues 105 and 165 , the latter being the active-site residue of glutamic acid. It is easier to see that there are fewer substitutions in certain regions in a 'bar chart' (Fig. 5), where substitutions are shown as vertical bars emerging from a horizontal polypeptide chain. These features provide hints about which parts of the structure play particular roles in catalysis and subunit interactions; the slow rate of evolution of the enzyme may perhaps make these hints more significant.

The support of the Medical Research Council is gratefully acknowledged, as is the technical assistance of Mrs. C. Moss and Miss R. Sammons. This paper is a contribution from the Oxford Enzyme Group, which is supported by the Science Research Council.

\section{References}

Ambler, R. P. \& Brown, L. H. (1967) Biochem. J. 104, 784-825

Banner, D. W., Bloomer, A. C., Petsko, G. A., Phillips, D. C. \& Pogson, C. I. (1971) Cold Spring Harbor Symp. Quant. Biol. 36, 151-155.

Beaven, G. H. \& Holiday, E. R. (1952) Advan. Protein Chem. 7, 320-386

Burton, P. M. \& Waley, S. G. (1968) Biochim. Biophys. Acta 151, 714-715

Butler, P. J. G., Harris, J. I., Hartley, B. S. \& Leberman, R. (1969) Biochem. J. 112, 679-689

Corran, P. H. \& Waley, S. G. (1973) FEBS Lett. 30, 97-99

Corran, P. H. \& Waley, S. G. (1974) Biochem. J. 139, 1-10

Dayhoff, M. O. (1972) Atlas of Protein Sequence and Structure, vol. 5, p. 50, National Biomedical Research Foundation, Washington, D.C.

Dixon, H. B. F. \& Perham, R. N. (1968) Biochem. J. 109, 312-314 
Furth, A. J., Milman, J. D., Priddle, J. D. \& Offord, R. E. (1974) Biochem. J. 139, 11-25

Hirs, C. H. W. (1956) J. Biol. Chem. 219, 611-621

Johnson, L. N. \& Waley, S. G. (1967) J. Mol. Biol. 29, 321-322

Kolb, E., Harris, J. I. \& Bridgen, J. (1974) Biochem. J. 137, 185-197

Krietsch, W. K. G., Pentchev, P. G., Klingenburg, H., Hofstatter, T. \& Bucher, T. (1970) Eur. J. Biochem. 14, 289-300.

Miller, J. C. \& Waley, S. G. (1971a) Biochem. J. 122, 209-218
Miller, J. C. \& Waley, S. G. (1971b) Biochem. J. 123, 163-170

Moore, S., Spackman, D. H. \& Stein, W. H. (1958) Anal. Chem. 30, 1185-1206

Norton, I. L., Pfuderer, P., Stringer, C. D. \& Hartman, F. C. (1970) Biochemistry 9, 4952-4958

Offord, R. E. (1966) Nature (London) 211, 591-593

Raftery, M. A. \& Cole, R. D. (1963) Biochem. Biophys. Res. Commun. 10, 467-472

Scoffone, E., Fontana, A.\& Rocchi, R.(1968) Biochemistry 7, 971-979

Waley, S. G. \& Watson, J. (1953) Biochem. J. 55, 328-337 